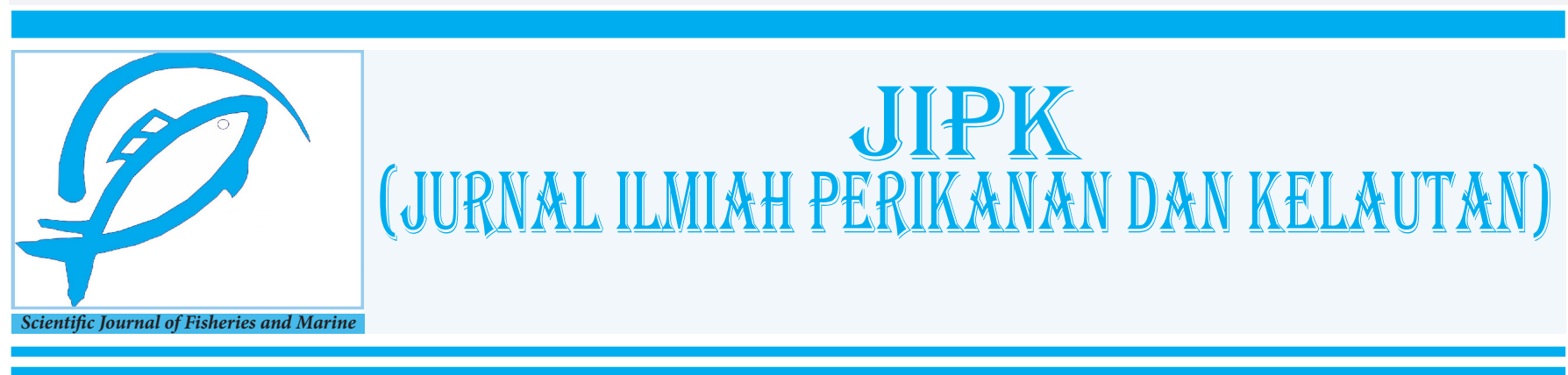

Research Article

\title{
The Effectiveness of Seaweeds as Biofilter for Reducing Wastewater Nutrient and Preventing Water Pollution from Hybrid Grouper Culture
}

\author{
Ratih Ida Adharini* (iD, Murwantoko, Namastra Probosunu, Riza Yulirano Setiawan, and Tony Budi \\ Satriyo
}

Department of Fisheries, Faculty of Agriculture, Universitas Gadjah Mada, Sleman, Yogyakarta, 55281. Indonesia

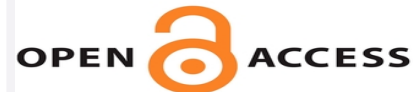

\section{$\underline{\text { ARTICLE INFO }}$}

Received: July 07, 2021

Accepted: September 19, 2021

Published: September 28, 2021

*) Corresponding author:

E-mail:ratih.adharini@ugm.ac.id

Keywords:

Nutrient Absorption

SGR

Aquaculture

Hybrid Grouper

Seaweed

This is an open access article under the CC BY-NC-SA license (https://creativecommons.org/ licenses/by-nc-sa/4.0/)

\begin{abstract}
Wastewater generated from hybrid grouper culture needs to be managed to improve water quality before being recirculated or discharged in the aquatic environment. Seaweed biofilter has been proposed in wastewater treatment technology for marine fish farming. This study aimed at comparing which of these species i.e. Ulva sp., Sargassum sp., Gelidium sp., and Dictyota sp. work best to absorb nutrient wastewater hybrid grouper culture. This research utilized these seaweed as treatments and controls with three replications using Completely Randomized Design. A statistical analysis was conducted to investigate the significant differences in the nutrient absorptions among various seaweed species by using ANOVA and least significant difference. Non-parametric tests namely Kruskal-Walis, Mann-Whitney, and t-test were used with confidence interval of $95 \%$. The results revealed that Ulva sp. has the best ability to reduce the nitrogen by $80 \%$, while Dictyota sp. able to reduce phosphate generated from wastewater of hybrid grouper culture by $88 \%$. While the highest absorbtion of Total Kjeldahl nitrogen $(104 \%)$ and phosphate (182\%) that were stored in thallus were performed by Ulva sp.. Ulva sp. had the best performance and highest growth rate $\left(1.9 \% \mathrm{~d}^{-1}\right)$ as biofilter in hybrid grouper cultivation than other species. Ulva sp. has great potential as a commodity to be used in the Integrated Multi Trophic Aquaculture (IMTA) system for aquaculture sustainability.
\end{abstract}

Cite this as: Adharini, R. I., Murwantoko, Probosunu, N., Setiawan, R. Y., \& Satriyo, T. B. (2021). The Effectiveness of Seaweeds as Biofilter for Reducing Wastewater Nutrient and Preventing Water Pollution from Hybrid Grouper Culture. Jurnal Ilmiah Perikanan dan Kelautan, 13(2):133-143. http://doi.org/10.20473/jipk.v13i2.28105 


\section{Introduction}

The global demand for animal-based protein, especially fish, is growing. According to FAO (2020) the global fish consumption reached 156 million tonnes in 2018. The technology in fish farming and aquaculture has been accelerated to meet the demand of protein food. In Indonesia, grouper, one of the highly demanded fish, has become one of the most important fish products and one of the most traded commodities in the South East Asia. Grouper farming is considered more sustainable compared to the wild catch system as it reduces the overfishing of wild grouper. According to Ministry of Maritime Affairs and Fisheries, the production number of grouper has increased by 11.95 kilotonnes in 2012 to 70.29 kilotonnes in 2017 (KKP, 2018). The giant tiger grouper (Epinephellus fuscoguttatus-lanceolatus) is a hybrid species of the tiger and giant grouper that is cultured due to its rapid growth and high salinity tolerance (De et al., 2014; Liang et al., 2013), and their resistance to diseases (Anita and Dewi, 2020). In addition, it may be cultured at a relatively low salinity approximately 14-20 ppt in highland areas at $393 \mathrm{~m}$ heigh above sea level and far from the coast.

The intensive culture of hybrid grouper require better aquaculture management system. Wastes from this intensive aquaculture may contain the accumulation of uneaten feed and fecal droppings of cultured fish. Solid waste can increase the level of nitrogenous compounds and stresses the cultured fish (Akinwole et al., 2016). Fish may be unable to utilize a major percentage of nitrogen and phosphorous which are included as the main component of feed, potentially resulting in environmental pollution. These nutrients when they are released into the environment at high concentrations pose as waste, may potentially harm fishes and other aquatic organisms. They may lead to increase the dissolved and suspended solids, as well as water turbidity. If solid waste in aquaculture remains in the culture system, the activity of aerobic bacteria may increase biological and chemical oxygen demand and therefore deplete oxygen availability (Santhi et al., 2017). Furthermore, as mentioned by Edwards et al. (2015), the uses of pellets in intensive aquaculture systems may trigger eutrophication, due to the input of excess phosphorus and nitrogen of the water that potentially causing the harmful algal blooms (HABs).

Hence, efforts should be made to control and make use of the nutrient waste. One of the approaches that have a potential to minimize the nutrient wastewater is by using seaweed as a biofilter (Marinho-Soriano et al., 2009; Laramore et al., 2018; Troell et al., 2009).
Seaweed biofilter has been proposed in wastewater treatment technology in marine fish aquaculture due to its environmental benefit, abundant availability, and affordable cost (Arumugam et al., 2018). However, it is also crucial to choose the appropriate seaweed species that can be applied as biofilter in order to reduce nutrient pollution in water, improve water quality, fish growth, and maximize the economic value of the seaweed itself. In addition, the use of seaweed as a biofilter and bioremediator has been extensively investigated, such as Ulva, Palmaria palmata, Gracilaria, Kappaphycus, and Hypnea aspera (Trianti and Adharini, 2020; Andayani et al., 2016; Anibal et al., 2013; Carneiro et al., 2011; Castellar et al., 2015; Elizondo-González et al., 2018; Hayashi et al., 2008; Kang et al., 2011; Laramore et al., 2018; Neori et al., 2003; Ribeiro et al., 2017; Tremblay-Gratton et al., 2018).

Seaweeds have been claimed to have the ability to lower nutrient pollutions in the water. Nevertheless, their use as biofilter must be mutually beneficial to the cultured fish and the surrounded ecosystem. Whereas, the effectiveness of each seaweed species as a biofilter varies (Kang et al., 2011). It may depend on water volume and circulation, initial biomass, water quality, and seaweed's physiology (Hayashi et al., 2008). Each seaweed has a different life suitability tolerance which impacts in its capacity to carry out the nutrient removal process, to survive, and to grow.

Hybrid grouper farming systems in the highlands area with the salinity around 14-20 ppt, require an appropriate seaweed species as a biofilter that can tolerate the water conditions and work effectively. The study of seaweed as biofilter for hybrid grouper culture is still relatively limited. Hence, the research aimed at comparing the ability of these species i.e. Sargassum sp., Dictyota sp., Gelidium sp., and Ulva sp. as biofilter in hybrid grouper culture at relatively low salinity condition. The results of this study are expected to reduce nutrient wastewater in hybrid grouper farming at low salinity, allowing the wastewater to be recirculated and reducing the impact of eutrophication if the wastewater is discharged to aquatic environment.

\section{Materials and Methods}

\subsection{Sample Collection and Acclimatization}

Some seaweeds namely Chaetomorpha sp., Gracilaria sp., Caulerpa sp., Ulva sp., Sargassum sp., Padina sp., Dictyota sp. and Gelidium sp., were gained from Trenggole Beach, southern of Yogyakarta. These seaweeds were cleaned, and then acclimated in four 
stages, from the salinity of 30, 25, 20, and 15 ppt. Each stage of salinity reduction was acclimated for three days. These steps were conducted to approach the wastewater culture condition (14-20 ppt). The acclimation used aerated closed system, and water quality parameter was observed continually. The result showed that Ulva sp., Sargassum sp., Dictyota sp., and Gelidium sp. were able to survive. Therefore these seaweeds were utilized for the subsequent tests.

\subsection{Methods}

\subsubsection{Experimental design}

The wastewater was obtained from the hybrid grouper farms at the highland area located in northern Yogyakarta that is fed by megame pellet size 3. Hybrid grouper wastewater aquaculture containing nutrient waste is accommodated in temporary tanks, then the wastewater is transferred to aquariums containing different seaweeds according to the treatment by outdoor experiment with transparent roof (Figure 1). The wastewater was then contained in 15 aquariums with the volume of $15 \mathrm{~L}$ each. Every treatment used 3 grams of seaweeds per liter. Therefore, every treatment used 45 grams of seaweeds for $15 \mathrm{~L}$ of wastewater. The seaweeds which had been previously acclimated were tested as biofilters in grouper culture wastewater in a closed system without any addition of seawater, and equipped with aeration. The experimental design utilized Completed Randomized Design (CRD) consisting of P0 as control, P1 with Ulva sp., P2 with Sargassum sp., P3 with Gelidium sp., and P4 with Dictyota sp.. Additionally, every treatment has three replications.

\subsubsection{Parameter measurements}

The parameter of water quality such as temperature, $\mathrm{pH}$, salinity, Total Dissolved Solids (EZ-9909 5 in 1), and Dissolved Oxygen (DO Meter Lutron-5519), and TSS (filtration method) were observed every 4 days. The concentration of nitrate, phosphate, ammonia in wastewater were examined by test kit (Visicolour ECO) then observed under compact photometer (PF-12).

The efficiency of nutrient reduction was calculated using the following formula:

$$
\begin{aligned}
& \text { Nutrient reduction effectivity in water }(\%)= \\
& \text { (Water N0 - Water Nf)/(Water N0) x } 100
\end{aligned}
$$

where $\mathrm{NO}$ represented the concentration of nutrient on day 0 ; and $N f$ showed the concentration of nutrient on final day in wastewater.

The seaweeds' Total Kjeldahl Nitrogen (TKN) content was tested using Kjeldahl method, therefore, the phosphate content was analyzed through Spectrophotometry method. The absorption of TKN and phosphate by seaweeds was assumed by the percentage of TKN and phosphate addition in the seaweed thallus based on the following formula:

The Addition of $\mathrm{TKN}$ or phosphate in thallus $(\%)=$

$$
\text { (Cf-C0)/C0 x } 100 \text {. }
$$

where $C 0$ showed the concentration of TKN or phosphate on day 0 in thallus, and $C f$ represented the final concentration of TKN or phosphate in thallus.

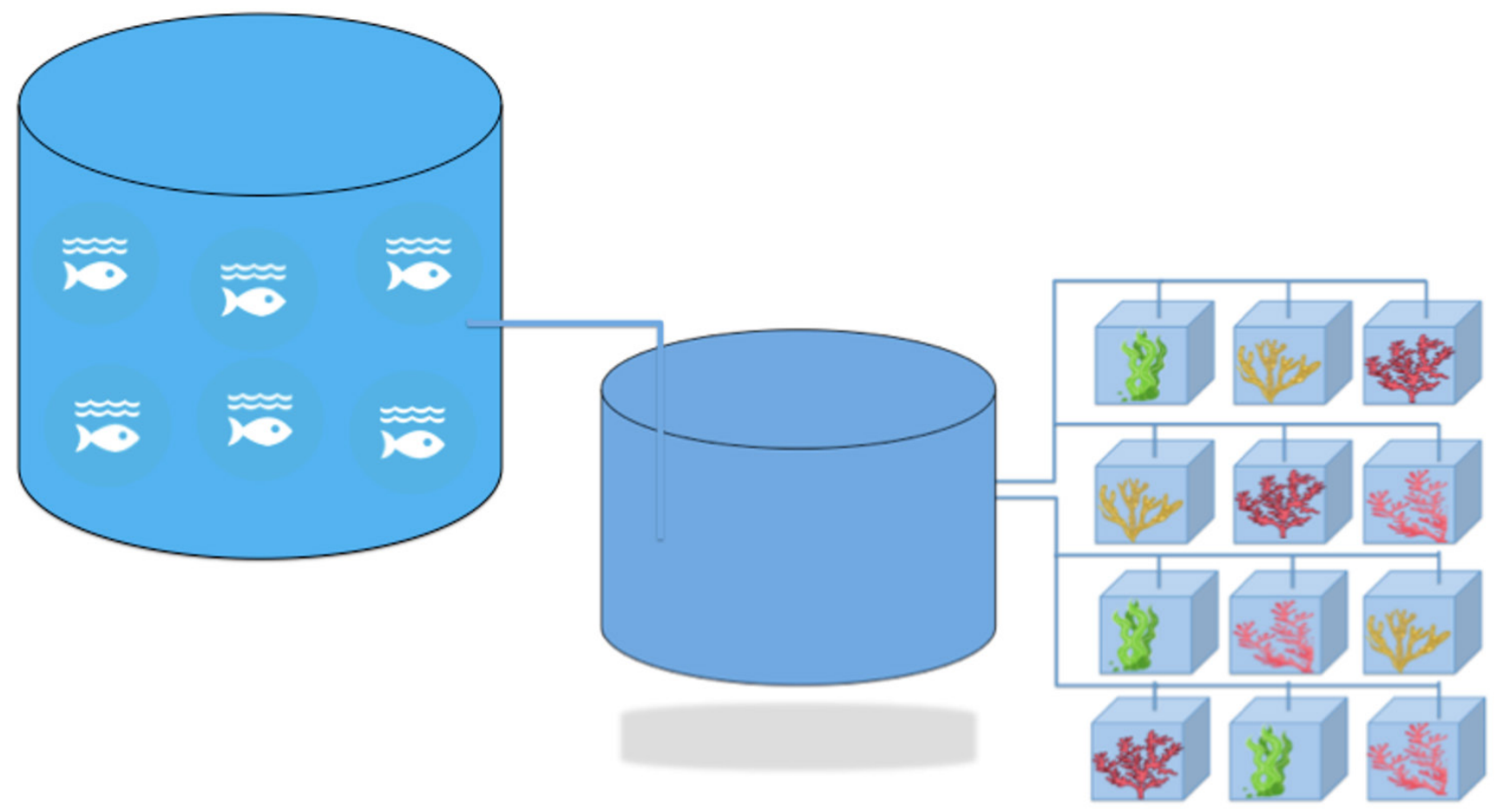

Figure 1. The schematic of experimental design. 
Specific Growth Rate (SGR) of seaweeds was calculated using the formula below:

SGR $\left(\% \mathrm{~d}^{-1}\right)=(\operatorname{Ln} \mathrm{Wt}-\mathrm{Ln} \mathrm{W} 0) / \mathrm{t} \times 100 \%$

where W0 represents wet weight on day 0 , and Wt represents final wet weight in $t$ time period.

\subsubsection{Data analysis}

In determining the data type (parametric or non-parametric), statistical assessment was performed through the normality and homogeneity tests. ANOVA test was used for the normally distributed and homogeneous data, to observe the significant differences between the treatments in each water quality parameter. Subsequently, it was analyzed using Least Significant Difference (LSD) analysis. Kruskal- Walis analysis and t-test or Mann-Whitney test were performed to analyze the data that were not homogeneous and normally distributed. A confidence level of $95 \%(\alpha=0.05)$ was used for all statistical tests. The data gathered in this study were analyzed using statistical software SPSS version 18.0.

\section{Results and Discussion}

\subsection{Water Quality of Hybrid Grouper Wastewater}

The water quality of hybrid grouper culture wastewater using seaweed during the experiments was recorded (Table 1). Significant variations in $\mathrm{DO}$ and $\mathrm{pH}$ were found between treatments. After the fourth day, the DO in all treatments decreased by $3 \mathrm{mg} \mathrm{L}^{-1}$ due to bacteria activity in decomposing wastewater, which required oxygen, resulting in decreased oxygen levels. However, DO level elevated afterward, and its maximum was recorded on the twelfth day of the treatment with Ulva sp. at $11.4 \mathrm{mg} \mathrm{L}^{-1}$ in water temperature of about $29^{\circ} \mathrm{C}$, indicating a substantial difference from the other species. Furthermore, the DO dropped to an average of $6.1 \mathrm{mg}$ $\mathrm{L}^{-1}$ on the twentieth day after increasing on the twelfth and sixteenth days.

The Ulva sp. and Dictyota sp. treatments had a comparatively higher DO level than the control since these two species had exceptional metabolism, survival ability, and photosynthesis process, resulting in higher DO level in aquaculture effluent. Meanwhile, because the metabolic process was disrupted to adjust to the conditions of wastewater quality, the DO content of the treatments with Sargassum sp. and Gelidium sp. was lower than the control, and thus the photosynthetic process was suboptimal. Ulva sp. and Dictyota sp. were also found to have a higher $\mathrm{pH}$ (Table 1). Because these seaweeds utilize bicarbonate for metabolism, the amount of $\mathrm{H}^{+}$in the water decreases, resulting in an increase in $\mathrm{pH}$. The concentration of dissolved $\mathrm{CO}_{2}$ and nitrification process will increase $\mathrm{H}^{+}$, which caused a $\mathrm{pH}$ decrease in this wastewater treatment (Schuenhoff et al., 2003). To summarize, Ulva sp. and Dictyota sp. have the ability to regulate the $\mathrm{pH}$ of less-than-ideal water conditions for aquatic life.

\subsection{Nutrient Reduction in Wastewater}

The nutrient reduction that consists of ammonia, nitrate, and phosphate concentration during the experiment was record (Figure 2). The ammonia content in the wastewater treated with Ulva sp. was effectively decreased to $0.57 \pm 0.04 \mathrm{mg} \mathrm{L}^{-1}(64 \%)$ on the fourth day, the lowest among the treatments. The concentration of ammonia in all treatments increased on the sixteenth day before falling to $74 \%$ on the twentieth day (Figure 2a). The growing ammonia concentration persisted until the sixteenth day, implying that the process of converting ammonium to nitrate was disturbed subsequently as a result of a drop in water temperature, reducing the ability of nitrifying bacteria to break down ammonia. Total ammonium nitrogen (TAN) removal is effective, and peaks in the summer when air and water temperatures rise (Matos et al. 2006). The ability of a biofilter to absorb nutrients is also regulated by temperature and water exchange rate under varied environmental circumstances (Abreu et al., 2011).

The nitrate concentration in wastewater treated with Ulva sp. grew until the fourth day, and then it steadily fell to $1.5 \pm 0.3 \mathrm{mg} \mathrm{L}^{-1}$. On the twentieth day of treatment, the nitrate level had dropped by $80 \%$. Meanwhile, the other treatments exhibited a rise in nitrate concentration (Figure 2b). This increase might be caused the condition of the nitrification process, which is influenced by environmental parameters. Roleda and Hurd (2019) stated that nutrient absorption are influenced by several factors, such as water movement, light, temperature, carbon dioxide, and salinity. The Ulva sp. absorbed nitrate faster than the other treatments (control; Sargassum sp.; Gelidium sp.; and Dictyota sp.). Furthermore, Ulva sp. demonstrated the most effective nitrate reduction starting on the fourth day, whereas the other seaweed treatments exhibited a drop by the eighth day. A similar finding is shown by Castellar et al. (2015), which stated that Ulva was able to decrease nitrogen nutrients more efficiently than Gracilaria birdiae. This nitrate content drop suggests that the seaweeds have absorbed the nitrate in the water, which serves as a nutrient removal system. Ulva absorbs dissolved inorganic nitrogen in less than one hour, and stores nitrate in the thallus as an internal reserve (Anibal et al. (2013). 
Table 1. The dynamics of water quality parameter of wastewater during experiments with different seaweeds species

\begin{tabular}{|c|c|c|c|c|c|c|c|}
\hline & & \multicolumn{6}{|c|}{ Concentration on day } \\
\hline & & $\mathbf{0}$ & 4 & 8 & 12 & 16 & 20 \\
\hline \multirow{5}{*}{ Salinity } & $\mathrm{P} 0$ & $14.43 \pm 0.12$ & $14.80 \pm 0.17$ & $15.20 \pm 0.15$ & $15.40 \pm 0.12$ & $15.90 \pm 0.31$ & $16.13 \pm 0.26$ \\
\hline & P1 & $14.33 \pm 0.37$ & $15.10 \pm 0.00$ & $15.60 \pm 0.00$ & $15.63 \pm 0.03$ & $16.43 \pm 0.09$ & $16.43 \pm 0.03$ \\
\hline & $\mathrm{P} 2$ & $14.47 \pm 0.22$ & $14.53 \pm 0.12$ & $15.27 \pm 0.18$ & $15.47 \pm 0.20$ & $16.03 \pm 0.23$ & $16.17 \pm 0.22$ \\
\hline & P3 & $14.50 \pm 0.03$ & $15.07 \pm 0.09$ & $15.60 \pm 0.10$ & $15.80 \pm 0.12$ & $16.30 \pm 0.12$ & $16.60 \pm 0.12$ \\
\hline & $\mathrm{P} 4$ & $14.55 \pm 0.03$ & $15.17 \pm 0.09$ & $15.70 \pm 0.06$ & $15.63 \pm 0.33$ & $16.40 \pm 0.06$ & $16.57 \pm 0.13$ \\
\hline \multirow{5}{*}{$\mathrm{pH}$} & $\mathrm{P} 0$ & $7.17 \pm 0.05$ & $7.52 \pm 0.12$ & $7.90 \pm 0.09$ & $7.94 \pm 0.04$ & $8.21 \pm 0.05$ & $7.67 \pm 0.05$ \\
\hline & P1 & $7.30 \pm 0.02$ & $7.86 \pm 0.10$ & $8.21 \pm 0.10$ & $8.19 \pm 0.09$ & $8.19 \pm 0.05$ & $7.67 \pm 0.09$ \\
\hline & $\mathrm{P} 2$ & $7.26 \pm 0.04$ & $7.10 \pm 0.01$ & $7.45 \pm 0.04$ & $7.77 \pm 0.04$ & $8.07 \pm 0.07$ & $7.73 \pm 0.04$ \\
\hline & P3 & $7.26 \pm 0.02$ & $7.31 \pm 0.12$ & $7.50 \pm 0.03$ & $7.97 \pm 0.08$ & $7.92 \pm 0.04$ & $7.41 \pm 0.04$ \\
\hline & $\mathrm{P} 4$ & $7.27 \pm 0.04$ & $7.44 \pm 0.06$ & $7.92 \pm 0.02$ & $8.23 \pm 0.07$ & $8.26 \pm 0.06$ & $7.68 \pm 0.01$ \\
\hline \multirow{5}{*}{ TDS } & $\mathrm{P} 0$ & $16.43 \pm 0.12$ & $16.43 \pm 0.20$ & $17.03 \pm 0.24$ & $17.13 \pm 0.19$ & $18.10 \pm 0.20$ & $18.13 \pm 0.24$ \\
\hline & P1 & $16.23 \pm 0.49$ & $16.80 \pm 0.06$ & $17.50 \pm 0.06$ & $17.53 \pm 0.09$ & $18.50 \pm 0.06$ & $18.57 \pm 0.07$ \\
\hline & P2 & $16.30 \pm 0.12$ & $16.47 \pm 0.27$ & $17.10 \pm 0.20$ & $17.26 \pm 0.22$ & $18.13 \pm 0.23$ & $18.17 \pm 0.32$ \\
\hline & P3 & $16.00 \pm 0.29$ & $16.73 \pm 0.03$ & $17.50 \pm 0.10$ & $17.67 \pm 0.09$ & $18.50 \pm 0.15$ & $18.43 \pm 0.18$ \\
\hline & $\mathrm{P} 4$ & $16.13 \pm 0.19$ & $16.77 \pm 0.12$ & $17.57 \pm 0.03$ & $17.70 \pm 0.00$ & $18.67 \pm 0.09$ & $18.43 \pm 0.12$ \\
\hline \multirow{5}{*}{ TSS } & $\mathrm{P} 0$ & $2.53 \pm 0.11$ & $1.04 \pm 0.08$ & $0.23 \pm 0.06$ & $0.66 \pm 0.11$ & $0.53 \pm 0.09$ & $0.33 \pm 0.00$ \\
\hline & P1 & $2.37 \pm 0.02$ & $1.33 \pm 0.22$ & $0.20 \pm 0.10$ & $0.58 \pm 0.13$ & $0.44 \pm 0.05$ & $0.37 \pm 0.03$ \\
\hline & $\mathrm{P} 2$ & $2.57 \pm 0.08$ & $1.03 \pm 0.13$ & $0.32 \pm 0.14$ & $0.38 \pm 0.10$ & $0.47 \pm 0.12$ & $0.40 \pm 0.05$ \\
\hline & P3 & $2.67 \pm 0.04$ & $1.54 \pm 0.14$ & $0.17 \pm 0.11$ & $0.50 \pm 0.11$ & $0.66 \pm 0.08$ & $0.43 \pm 0.04$ \\
\hline & P4 & $2.59 \pm 0.04$ & $1.17 \pm 0.14$ & $0.36 \pm 0.09$ & $0.54 \pm 0.12$ & $0.70 \pm 0.03$ & $0.43 \pm 0.09$ \\
\hline \multirow{5}{*}{ DO } & $\mathrm{P} 0$ & $5.67 \pm 0.24$ & $3.20 \pm 0.47$ & $7.03 \pm 0.22$ & $9.30 \pm 0.21$ & $9.77 \pm 0.39$ & $6.23 \pm 0.28$ \\
\hline & P1 & $6.37 \pm 0.34$ & $3.30 \pm 0.49$ & $6.33 \pm 0.32$ & $11.57 \pm 0.09$ & $10.90 \pm 0.21$ & $6.20 \pm 0.17$ \\
\hline & $\mathrm{P} 2$ & $5.53 \pm 0.15$ & $2.60 \pm 0.15$ & $5.90 \pm 0.15$ & $8.63 \pm 0.27$ & $10.50 \pm 0.51$ & $5.63 \pm 0.27$ \\
\hline & P3 & $6.13 \pm 0.22$ & $2.87 \pm 0.97$ & $6.50 \pm 0.31$ & $10.13 \pm 0.41$ & $10.00 \pm 0.29$ & $5.90 \pm 0.29$ \\
\hline & P4 & $6.80 \pm 0.20$ & $3.10 \pm 0.15$ & $6.73 \pm 0.20$ & $10.07 \pm 0.41$ & $11.00 \pm 0.21$ & $6.23 \pm 0.28$ \\
\hline
\end{tabular}

Description: P0 (Control), P1 (Ulva sp.), P2 (Sargassum sp.), P3 (Gelidium sp.), P4 (Dictyota sp.).

During the treatment, the concentration of phosphorus steadily decreased until the twentieth day. However, on the twelfth day, Dictyota sp. had the quickest decline in phosphate concentration, reaching $0.73 \pm$ $0.09 \mathrm{mg} \mathrm{L}^{-1}(82 \%)$, while the lowest was $0.50 \pm 0.06 \mathrm{mg}$ $\mathrm{L}^{-1}(88 \%)$. Ulva sp., Gelidium sp., and Sargassum sp., on the other hand, were able to reduce phosphate concentrations by $83 \%, 76 \%$, and $70 \%$, respectively, on day 20 (Figure 2c). This decrease of phosphate concentration in wastewater in all treatments is because the phosphate can be readily absorbed and utilized by cells in the thallus. It can be proven that the content of Total Kjeldahl Nitrogen (TKN) and total phosphate in the thallus has increased, and then there has been an increase in growth until the end of this experiment. This is also confirmed by Arumugam et al. (2018) that phosphate was transfered extracellulary including absorption of phosphate by chemical bond formation and absorption by active sites on the surface of biosorbents. Meanwhile, intracellular transfer consists of biotransformation and intracellular phosphate accumulation.

Ulva sp. treatment showed the most significant reduction in ammonia in the water, followed by Sargassum sp., Gelidium sp., and Dictyota sp.. However, there were no significant variations in the percent reduction of ammonia in the water in any treatments (Figure 3a). Although it was not statistically different from Sargassum $\mathrm{sp}$. and Gelidium sp., the treatment using Ulva sp. showed the highest percentage of nitrate reduction in water, reducing the nitrate level by $80 \%$ (Figure $3 \mathrm{~b}$ ). Furthermore, Dictyota sp. showed the most significant percentage reduction in phosphate $(88 \%)$; it was considerably different from the control, Sargassum sp., and Dictyota sp., but not statistically different from Ulva sp. (83\%) (Figure 3c). 

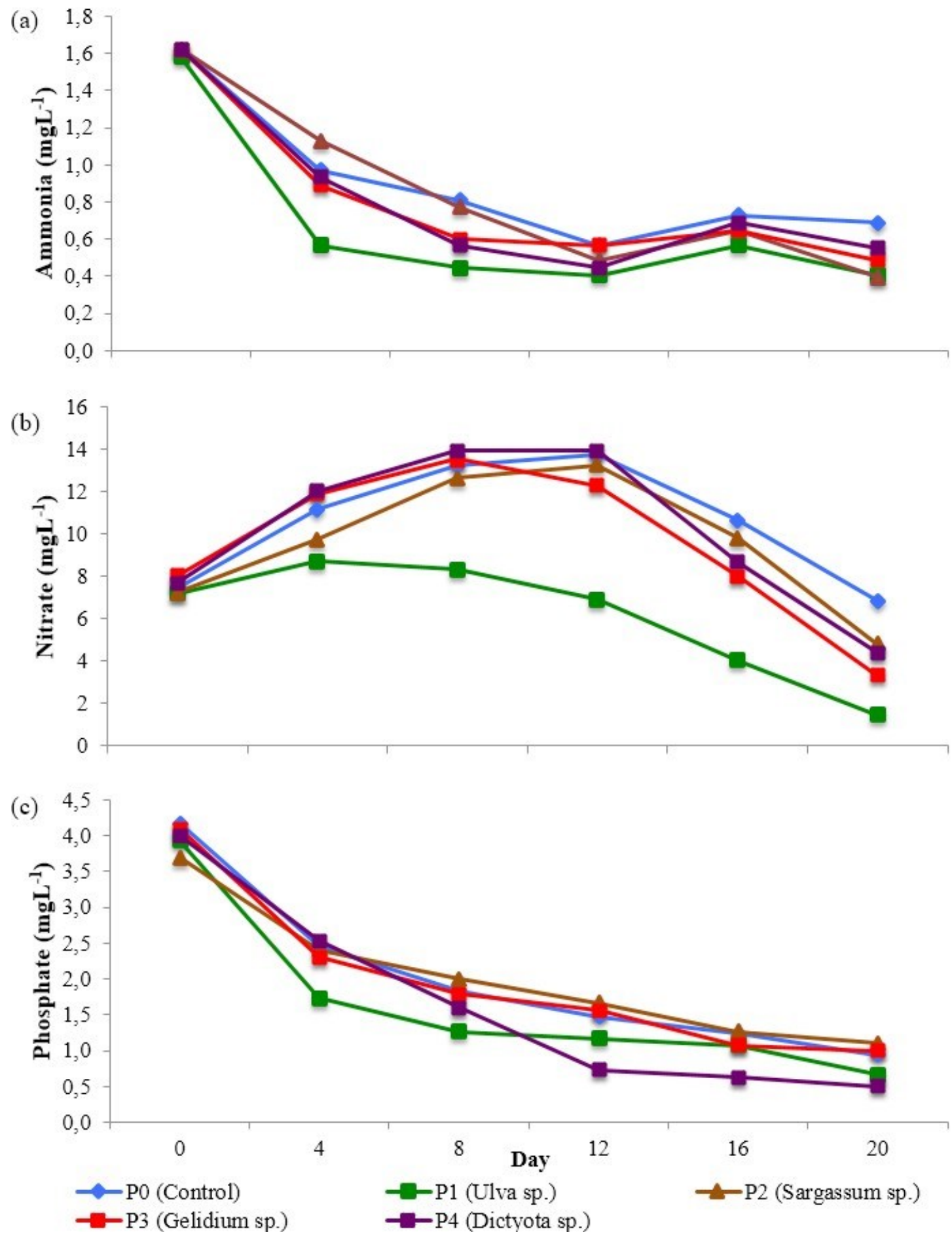

Figure 2. The concentration change of (a) Ammonia $\left(\mathrm{NH}_{3}\right)$; (b) Nitrate $\left(\mathrm{NO}^{3-}\right)$; (c) Phosphate $\left(\mathrm{PO}_{4}^{3-}\right)$ in hybrid grouper culture wastewater for twenty days with different seaweeds during experiment.

\subsection{Absorbtion of Total Kjeldahl Nitrogen (TKN) and Total Phosphate of Wastewater into the Thallus}

The addition of total phosphate content in seaweed thallus is higher than the addition of TKN (Figure 4). Ulva sp. had the greatest effective absorption of $\mathrm{N}$ and $\mathrm{P}$ from wastewater, owing to the largest percentage addition of TKN and phosphate levels in its thallus.
In comparison to Ulva sp., Dictyota sp., Sargassum sp., and Gelidium sp. showed the lowest N and P absorption. The ability of seaweed to absorb oreliminate nutrients in water is considered to be based on the percentage addition of TKN and phosphate concentrations in the thallus. As a result, the larger percentage of TKN and phosphate addition may indicate that the seaweed has better effectiveness to absorb and utilize these nutrients for metabolism and growth process. 
(a)

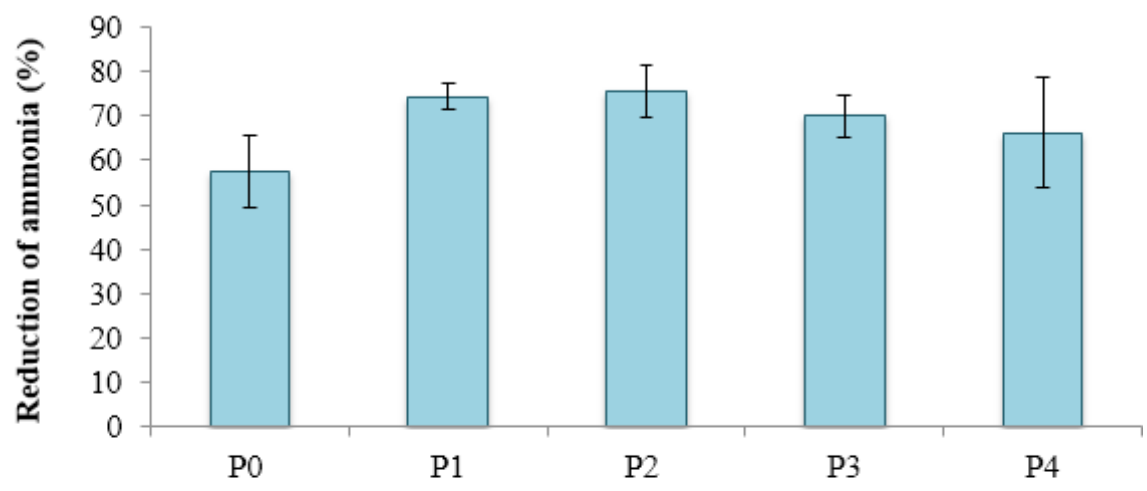

(b)

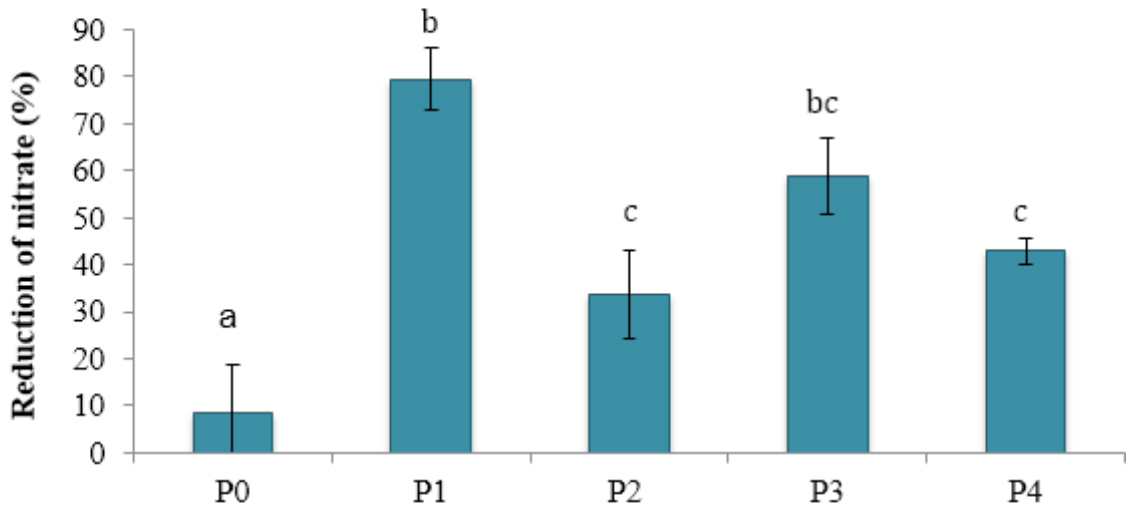

(c)

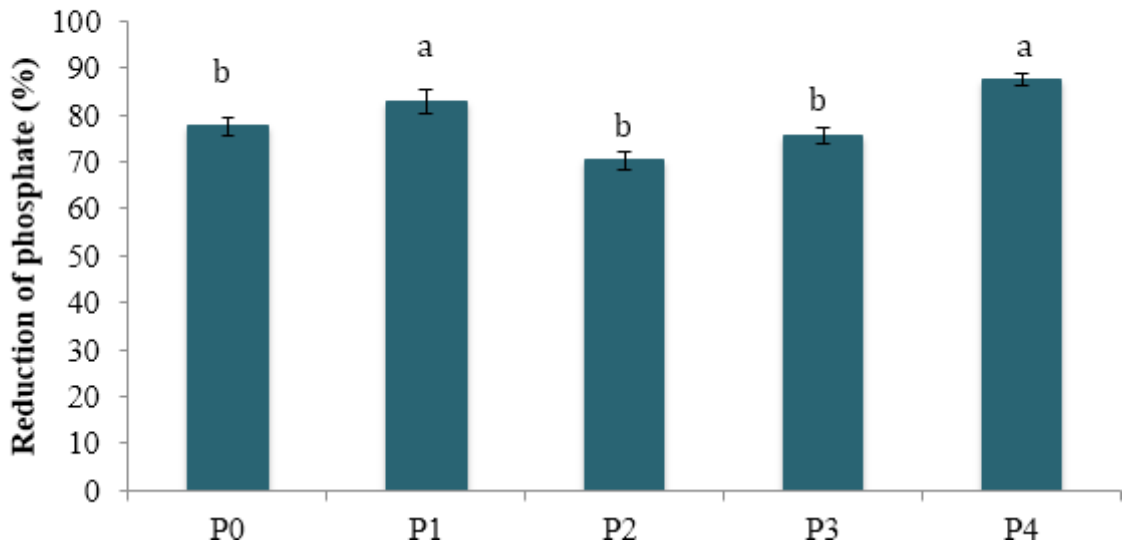

Figure 3. Reduction of (a) Ammonia (NH3); (b) Nitrate (NO־3--); (c) Phosphate (PO43-) in hybrid grouper culture wastewater for twenty days with different seaweeds. Description: P0 (Control), P1 (Ulva sp.), P2 (Sargassum sp.), P3 (Gelidium sp.), P4 (Dictyota sp.). Each data point is mean $\pm \mathrm{SD}(\mathrm{n}=3)$. Different superscripts at each bar in the same graph shows that there are significant differences $(\mathrm{p}<0.05)$.

Ulva sp. had the highest TKN addition percentage (104\%), while Gelidium sp. had the lowest (3\%) (Figure 4a). However, not all absorbed nutrients were digested and retained because they returned to the water in different forms; high levels of ammonium and nitrate in water produce an increase in nitrogen accumulation in thallus (Ribeiro et al., 2017). The percent addition of phosphate tended to be greater than that of TKN content in the seaweed thallus. It could be because the phosphate concentration in water was higher than ammonia but lower than nitrate. Ulva sp. had the highest percentage addition of phosphate content (182\%), whereas Gelidium sp. had the lowest (9\%) (Figure 4b). However, according to Ribeiro et al. (2017), not all of the absorbed inorganic phosphate was used for growth because it can also boost pigment, protein, and phosphorus levels in the thallus.

\subsection{SGR of Seaweed}

Ulva sp. had the most optimum SGR at 1.9\% $\mathrm{d}^{-1}$, Dictyota sp. at $0.36 \% \mathrm{~d}^{-1}$, and Gelidium sp. at $0.25 \%$ $\mathrm{d}^{-1}$ (Figure 5). Ulva sp. has the greatest SGR due to its superior capacity to cope with harsh wastewater conditions. In addition, Ulva sp. has a high tolerance and good environmental adaptability to variations in irradiance, 
(a)

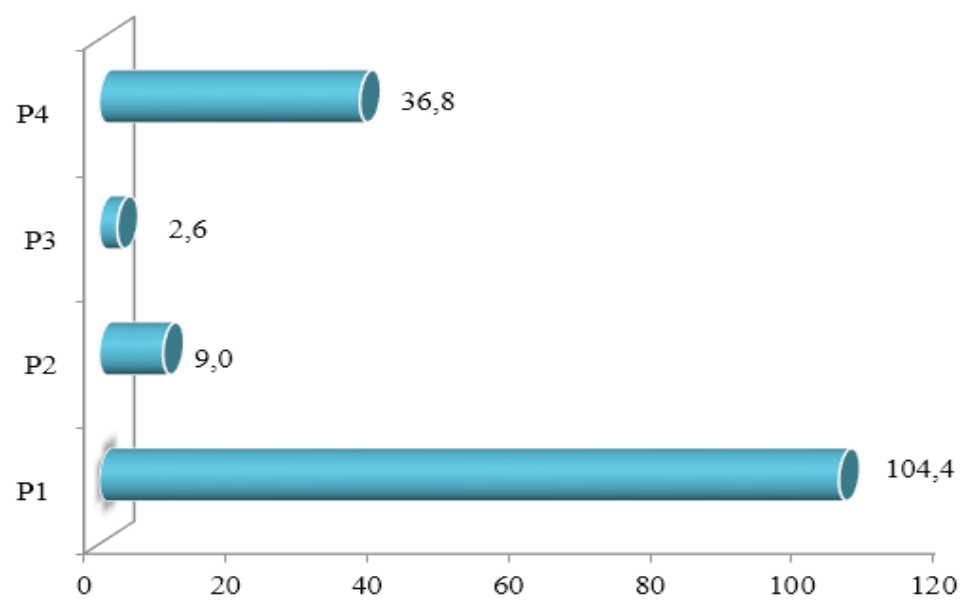

(b)

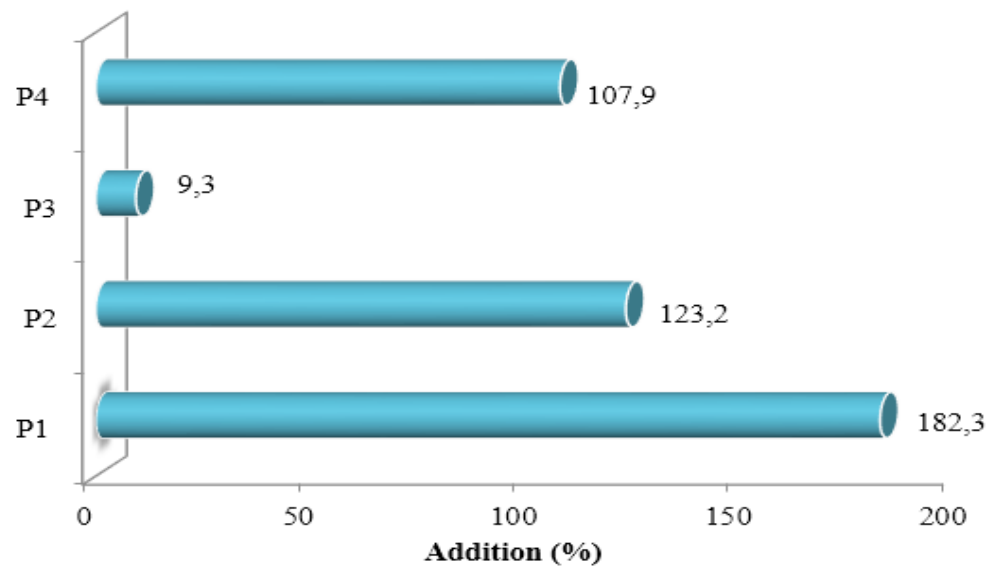

Figure 4. Percent addition of TKN (a) and Phosphate (b) contents in thallus of different seaweeds for twenty days. Description: P1 (Ulva sp.), P2 (Sargassum sp.), P3 (Gelidium sp.), P4 (Dictyota sp.)

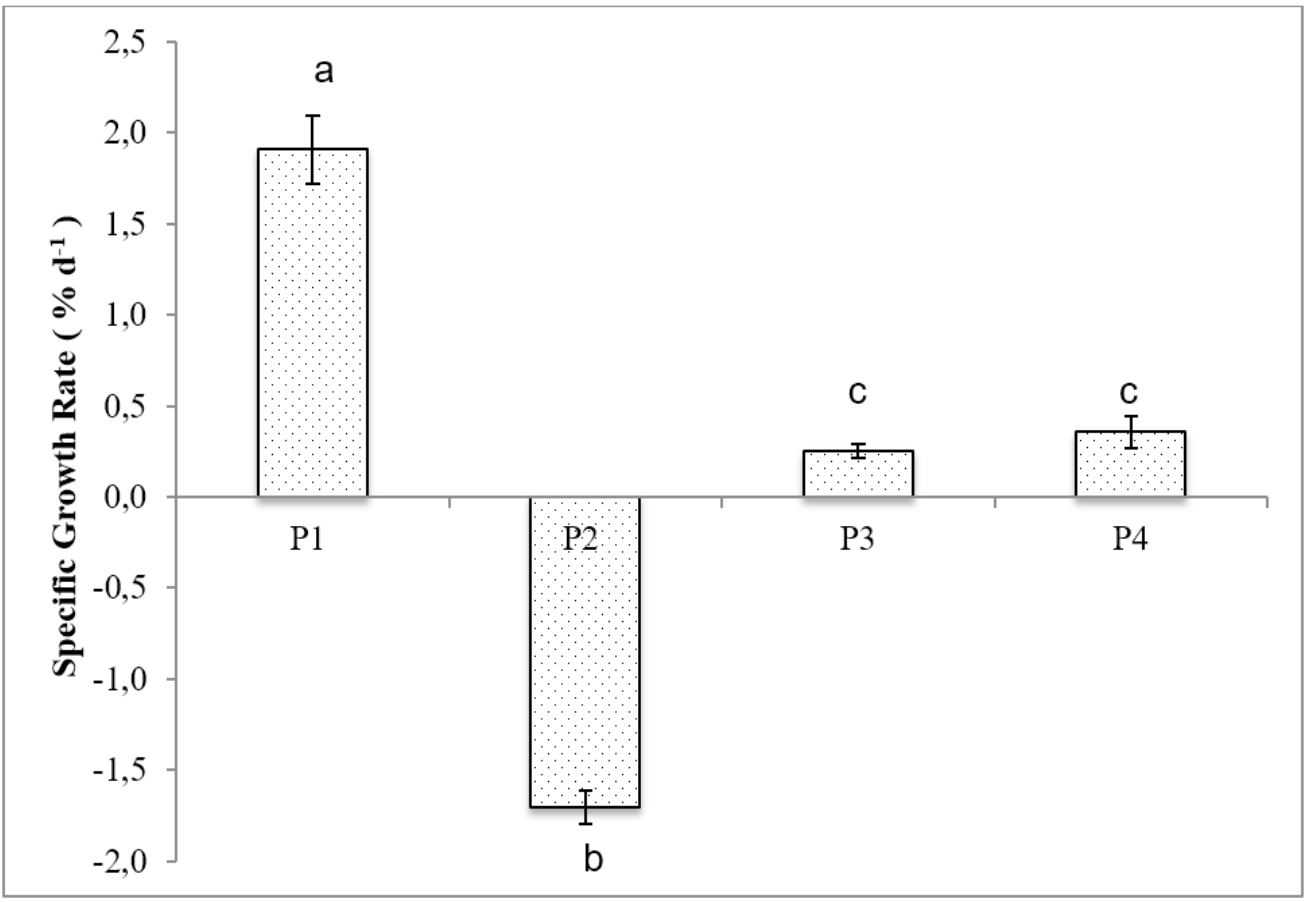

Figure 5. Specific Growth Rate of different seaweeds for twenty days in wastewater of hybrid grouper culture. Description: P1 (Ulva sp.), P2 (Sargassum sp.), P3 (Gelidium sp.), P4 (Dictyota sp.). Each data point is mean \pm SD $(n=3)$. Different superscripts at each bar shows that there are significant differences $(p<0.05)$. 
temperature, salinity, and humidity (Castellar et al. 2015; Mantri et al. 2020). Tsagkamilis et al. (2010) also affirms this, stating that Ulva sp. can thrive in low salinity environments. Ulva sp. also had the highest ability to absorb nutrients than the other seaweeds examined in this study. Ulva sp. has the most expansive thallus surface to uptake nutrients than the other seaweed species did. According to Rosenberg and Ramus (1984), the ratio of thallus surface area to volume has a positive association with nutrient uptake rate. Moreover, Ulva sp. can use these nutrients for metabolic activities, giving it the highest SGR among the treatments.

Sargassum sp. had the lowest SGR because some thalli died, resulting in thalli that were fragile and flabby, affecting the ultimate weight and SGR. Temperature and salinity, as well as the carbon and nitrogen content of the thallus, are limiting environmental variables (Li et al., 2019). Sargassum sp. was unable to resist the low salinity conditions, and as a result, it became inefficient in absorbing nutrients, resulting in the death of some thalli. Gelidium sp. thalli tips turned green, while Dictyota sp. thalli tips became pale and weak. This change in color to a whitish pale is known as ice-ice disease, and it is caused by stress in aquatic environmental circumstances that are not compatible with some species' tolerance. In this study, several Dictyo$t a$ sp. thalli tips were infected with ice-ice disease and fragmented because they could not withstand the hybrid grouper wastewater.

Hybrid grouper wastewater had relatively low salinity (14-20 ppt), whereas Gelidium, Dictyota, and Sargassum naturally live in water with a salinity of more than 25 ppt. This condition reduces the species' ability to survive, making it more susceptible to virus and bacterial infection, harming the thalli. In addition, the attachment of epiphytes, which are green mosses that stick to the dead white surface of the thallus, is common in some regions of the thalli that suffer from iceice disease. When tested in the Integrated Multi-Trophic Aquaculture (IMTA) system with red abalone, the same thing happened to Gracilaria chilencis, which was infected by filamentous algae (Macchiavello and Bulboa, 2014). Ulva sp., on the other hand, showed no signs of epiphytic infection in our study. Therefore, Ulva sp. optimally grows and efficiently absorbs nutrients better than Sargassum sp., Gelidium sp., and Dictyota sp.

\section{Conclusion}

Ulva sp. was proven to have the best effectiveness as biofilter to reduce and absorb nutrient in the grouper aquaculture wastewater compared to Sargas- sum sp., Gelidium sp., and Dictyota sp. Moreover, Ulva $\mathrm{sp}$. is easy to find, has highest survivability and growth rate. Therefore, Ulva sp. becomes a promising commodity of seaweed to be utilized in Integrated Multi Trophic Aquaculture (IMTA) system for sustainable aquaculture production and ecofriendly fisheries, as well as to prevent water pollution or eutrophication problems in aquatic environment.

\section{Acknowledgement}

The authors thanks to PT. INDMIRA to support this research.

\section{Authors' Contributions}

All authors have contributed to the final manuscript. The contribution of each author as follow, Adharini; lead and coordinated the research and publication process. Murwantoko and Probosunu; designed the research and write manuscript. Satriyo and Setiawan; analyzed the data and write manuscript. All authors; read and approved the final manuscript.

\section{Conflict of Interest}

The authors stated and declared that there is no conflict of interest in this research.

\section{Funding Information}

This research was funded by Indonesian Ministry of Research, Technology, and Higher Education with the research grant of PDUPT 2020 through Universitas Gadjah Mada with grant number : No. 2784/UN1/ DITLIT/DIT-LIT/PT/2020.

\section{References}

Abreu, M., Pereira, R., Yarish, C., Buschmann, A. H., \& Sousa-Pinto, I. (2011). IMTA with Gracilaria vermiculophylla: productivity and nutrient removal performance of the seaweed in a landbased pilot scale system. Aquaculture, 312:77-87.

Akinwole, A. O., Dauda, A. B. \& Ololade, O. A. (2016). Growth performance of african catfish (Clarias gariepinus) juveniles reared in wastewater treated with alum and Moringa oleifera seed. Journal of Aquaculture Research \& Development, 7(12):1000460.

Andayani, S., Yuwanita, R., \& Izzah, N. (2016). Biofilter application using seaweed (Gracilaria verru$\cos a$ ) to increase production of vannamei shrimp in traditional pond district Bangil-Pasuruan. Re- 
search Journal of Life Science, (3)1:16-22.

Anibal, J., Madeira, H. T., Carvalho, L. F., Esteves, E., Veiga-Pires, C., \& Rocha, C. (2013). Macroalgae mitigation potential for fish aquaculture effluents: an approach coupling nitrogen uptake and metabolic pathways using Ulva rigida and Enteromorpha clathrata. Environmental Science and Pollution Research, 21(23):13324-13334.

Anita, N. S., \& Dewi, N. N. (2020). Evaluation of hatching rate, growth performance, and survival rate of cantang grouper (Epinephelus fuscoguttatus $\mathrm{x}$ lanceolatus) in concrete pond at Situbondo, East Java, Indonesia. IOP Conf. Series: Earth and Environmental Science, 441:(2020) 012019.

Arumugam, N., Chelliapan, S., Kamyab, H., Thirugnana, S., Othman, N., \& Nasri, N. S. (2018). Treatment of wastewater using seaweed: a review. International Journal of Environmental Research and Public Health, 15, 2851

Carneiro, M. A. A., Freire, F. A. M., \& Marinho-Soriano, E. (2011). Study on biofiltration capacity and kinetics of nutrient uptake by Gracilaria cervicornis (Turner) J. Agardh (Rhodophyta, Gracilariaceae). Brazilian Journal of Pharmacognosy, 21(2):329-333.

Castellar, B., Pontes, M. D., Costa, W. d. M., Moura, L. C. F., Dias, G. E., Landuci, F. S., \& Reis, R. P. (2015). Biofiltering efficiency and productive performance of macroalgae with potential for integrated multi-trophic aquaculture (IMTA). Boletim do Instituto de Pesca, São Paulo, 41:763-770.

De, M., Ghaffar, M. A., \& Das, S. K. (2014). Temperature effect on gastric emptying time of hybrid grouper (Epinephelus spp.). AIP conference proceedings, 1614:616-618.

Edwards, P. (2015). Aquaculture environment interactions: past, present and likely future trends. Aquaculture, 447:2-14.

Elizondo-González, R., Quiroz-Gusmán, E., Escobedo-Fregoso, C., Magallón-Servín, P., \& Peña-Rodríguez, A. (2018) Use of seaweed Ulva lactuca for water bioremediation and as feed additive for white shrimp Litopenaeus vannamei. Peer Jornal, 6:e4459

FAO (2020). The state of world fisheries and aquaculture, sustainability in action. Rome: Food and Agriculture Organization of the United Nations.
Hayashi, L., Yokoya , N. S., Ostini, S., Pereira, R. T. L., Braga, E. S., \& Oliveira, E. C. (2008). Nutrients removed by Kappaphycus alvarezii (Rhodophyta, Solieriaceae) in integrated cultivation with fishes in re-circulating water. Aquaculture, 277:185-191.

Kang, Y. H., Park, S. R., \& Chung, I. K. (2011). Biofiltration efficiency and biochemical composition of three seaweed species cultivated in a fish-seaweed integrated culture. Algae, 26(1):97-108.

KKP (Ministry of Marine and Fisheries). (2018). Buku Pintar Kementerian Kelautan Perikanan. Pusat Data, Statistik, dan Informasi. Jakarta: Kementerian Kelautan dan Perikanan.

Laramore, S., Baptiste, R., Wills, P. S., \& Hanisak, M. D. (2018). Utilization of IMTA-produced Ulva lactuca to supplement or partially replaced pelleted diests in shrimps (Litopenaeus vannamei) reared in a clear water production system. Journal of Applied Phycology, 30:3603-3610.

Li, J., Liu, Y., Liu, Y., Wang, Q., Gao, X., \& Gong, Q. (2019). Effects of temperature and salinity on the growth and biochemical composition of the brown alga Sargassum fusiforme (Fucales, Phaeophyceae). Journal of Applied Phycology, 31:3061-3068.

Liang, H. F., Huang, D. K., Wu, Y. H., Wang, C. Q., \& Zhong, W. J. (2013). Effects of temperature and salinity on survival and food intake of grouper hybrid (Epinephelus lanceolatus + $\mathrm{x}$ Epinephelus fuscoguttatus $\left.{ }^{1}\right)$. Journal of Guangdong Ocean University, 33:22-26.

Macchiavello, J., \& Bulboa, C. (2014). Nutrient uptake efficiency of Gracilaria chilensis and Ulva lactu$c a$ in an IMTA system with the red abalone Haliotis rufescens. Latin American Journal of Aquatic Reseach, 42(3):523-253.

Mantri, V. A., Kazi, M. A., Balar, N. J., Gupta, V., \& Gajaria, T. (2020). Concise review of green algal genus Ulva Linnaeus. Journal of Applied Phycology, 32:2725-2741.

Marinho-Soriano, E., Nunes, S. O., Carneiro, M. A. A., Pereira, D. C. (2009). Nutrients' removal from aquaculture wastewater using the macroalgae Gracilaria birdiae. Biomass and Bioenergy, 33:327-331. 
Matos, J., Costa, S., Rodrigues, A., Pereira, R., \& Pinto, I. S. (2006). Experimental integrated aquaculture of fish and red seaweeds in Northern Portugal. Aquaculture, 252:31-42.

Neori, A., Msuya, F. E., Shauli, L., Schuenhoff, A., \& Shpigel, M. (2003). A novel three-stage seaweed (Ulva lactucai) biofilter design for integrated mariculture. Journal of Applied Phycology, 15:543-553.

Ribeiro, A. L. N. L., Chiozzini, V. G., Braga, E. S., \& Yokoya, N. S. (2017). Physiological responses and biofilter potential of Hypnea aspera (Rhodophyta, Gigartinales) cultivated in different availabilities of nitrate, ammonium, and phosphate. Journal of Applied Phycology, 29:683-694.

Roleda, M.Y., \& Hurd, C. L. (2019). Seaweed nutrient physiology: application of concepts to aquaculture and bioremediation. Phycologia, 58(5): 552562 .

Rosenberg, G., \& Ramus, J. (1984). Uptake of inorganic nitrogen and seaweed surface area: volume ratios. Aquatic Botany, 19:65-72.

Santhi, N., Deivasigamani, B., \& Subramanian, V. (2017). Studies on biodegradation of shrimp farm wastes by using of seaweeds. International Journal of Current Microbiology Applied Science, 6(1): 271-281.
Schuenhoff, A., Shpigel, M., Lupatsch, I., Ashkenazi, A., Msuya, F. E., \& Neori, A. (2003). A semi-resirculating, integrated system for the culture of fish and seaweed. Aquaculture, 221:167-181.

Tremblay-Gratton, A., Boussin, J. C., Tamigneaux, E., Vandenberg, G. W., \& Le Francois, N. R. (2018). Bioremediation efficiency of Palmaria palmata and Ulva lactuca for use in a fully resirculated cold-seawater naturalistic exhibit: effect of high $\mathrm{NO}_{3}$ and $\mathrm{PO}_{4}$ concentrations and temperature on growth and nutrient uptake. Journal of Applied Phycology, 30:1295-1304.

Trianti, C. M. \& Adharini, R. I. (2020). The utilization of Gracilaria verrucosa as shrimp ponds wastewater biofilter. E3S Web of Conferences 147, 02023 (2020). 3rd ISMFR

Troell, M., Joyce, A., Chopin, T., Neori, A., Buschmann, A. H., \& Fang, J.G. (2009). Ecological engineering in aquaculture - potential for integrated multi-trophic aquaculture (IMTA) in marine offshore systems. Aquaculture, 297:1-9.

Tsagkamilis, P., Danielidies, D., Dring, M. J., \& Katsaros, C. (2010). Removal of phosphate by the green seaweed Ulva lactuca in a small-scale sewage treatment plant (Ios Island, Aegean Sea, Greece). Journal of Applied Phycology, 22:331339 . 